\title{
U.S. Geological Survey (USGS) Western Region: Seabirds Coastal and Ocean Science
}

From the cold, high Arctic area of Alaska to the warm, tropical Pacific area of Hawai $i$, a diverse array of seabird species numbering in the millions of individuals live off the bounty of the Pacific Ocean. Many come to land only to nest and raise their youngthese are species supremely adapted for life on the water, whether it be near the coast or hundreds of miles at sea. Those seabirds that reside in the North Pacific year-round are joined each summer by millions of migrant birds that leave the southern hemisphere in winter for better feeding conditions in the north. Seabirds in the Pacific remain one of the great wildlife spectacles on the earth. Yet, seabirds face a number of threats such as oil spills, introduction of predators to their nesting islands, and conflicts with fisheries. State and Federal agencies require increasingly sophisticated information on population dynamics, breeding biology, and feeding ecology to successfully manage these species and their ecosystems. Within the Western Region of the USGS, scientists from the Alaska Science Center (ASC), Western Ecological Research Center (WERC), and Pacific Islands Ecosystems Research Center are leading the way in conducting research on many of these little known species. Their aim is to improve our understanding of seabirds in the Pacific and to provide information to support informed management of the birds and their ecosystems.

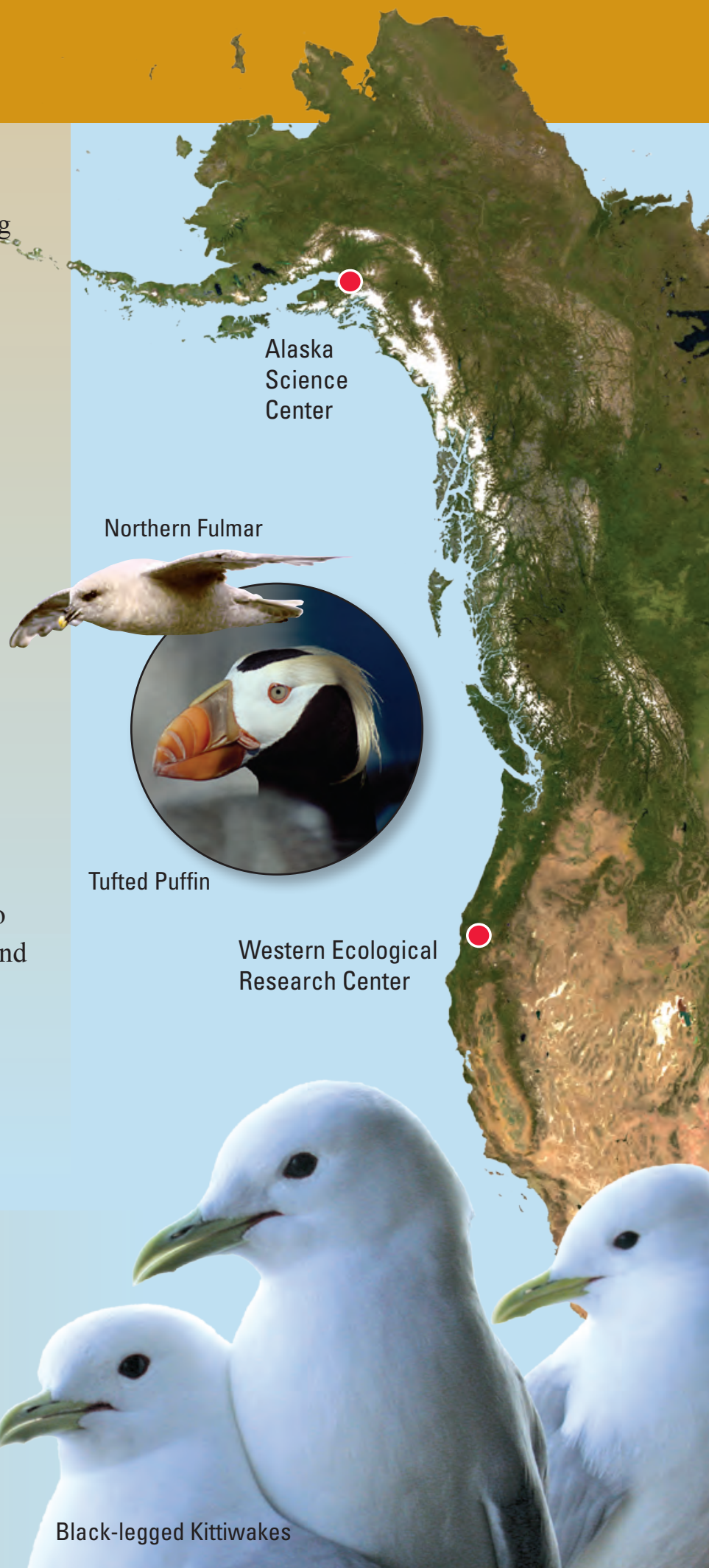

The U.S. Geological Survey (USGS) is the Nation's largest water, earth, and biological science and civilian mapping agency. The USGS serves the Nation by providing reliable scientific information to describe and to understand the Earth; to minimize loss of life and property from natural disasters; to manage water, biological, energy, and mineral resources; and to enhance and to protect our quality of life. 


\section{Monitoring Breeding, Behavios, and Population Ecology of Seabirds in Alaska}

Populations of seabirds in Alaska are larger and more diverse than seabirds in any similar region of the northern hemisphere. Alaska's extensive estuaries and offshore waters provide breeding, feeding, and migrating habitats for almost 100 million seabirds of 66 species. Breeding birds number about 50 million individuals of 38 species, which is 96 percent of all breeding seabirds in the continental United States. The catalog of known breeding sites includes more than 1,300 colonies ranging in size from a few birds to more than 2.5 million.

Seabirds are integral members of marine ecosystems and can serve as sensitive indicators of the health and status of these marine ecosystems. Measurements of abundance, demographic attributes, diets, behavior, and physiology of seabirds provide accurate real time "sensors" of local and large-scale changes in their marine environment.

Seabirds in Alaska include albatrosses, auklets, cormorants, fulmars, grebes, gulls, kittiwakes, loons, murrelets, murres, petrels, phalaropes, and puffins.

\section{Kittlitz's and Marbled Murrelet Research in National Parks and Wildlife Refuges}

USGS ASC continues its effort to better understand the status and ecology of the Kittlitz's Murrelet, a candidate species under the Endangered Species Act (ESA) and the Marbled Murrelet, presently listed as 'Threatened' under the ESA in the southern part of its range (Washington, Oregon, and California). USGS ASC, in collaboration with the U.S. Fish and Wildlife Service, is studying the nesting ecology of the Kittlitz's Murrelet on Kodiak and Agattu Islands in the Kodiak and Alaska Maritime National Wildlife Refuges. As part of a multi-year effort to study the breeding ecology and behavior of this species in the refuges, scientists have located 21 nests. Automatic cameras record aspects of behavior and biology; eggs and chicks are measured and monitored; and nesting habitat is being characterized. Monitoring of inland flying behavior and abundance helps assess seasonal patterns of attendance and characterize social behavior. USGS scientists also are studying Kittlitz's and Marbled Murrelets in Kenai Fjords National Park where they examine seasonal patterns of abundance and gather habitat data to relate
environmental characteristics to key population factors. Further analyses will focus primarily on more refined characterization

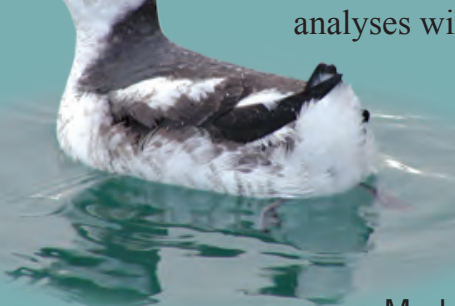
of murrelet habitats and on assessing long-term population trends-information essential to aiding management agencies in habitat conservation planning and to ESA listing discussions for both species of murrelet.

Marbled Murrelet

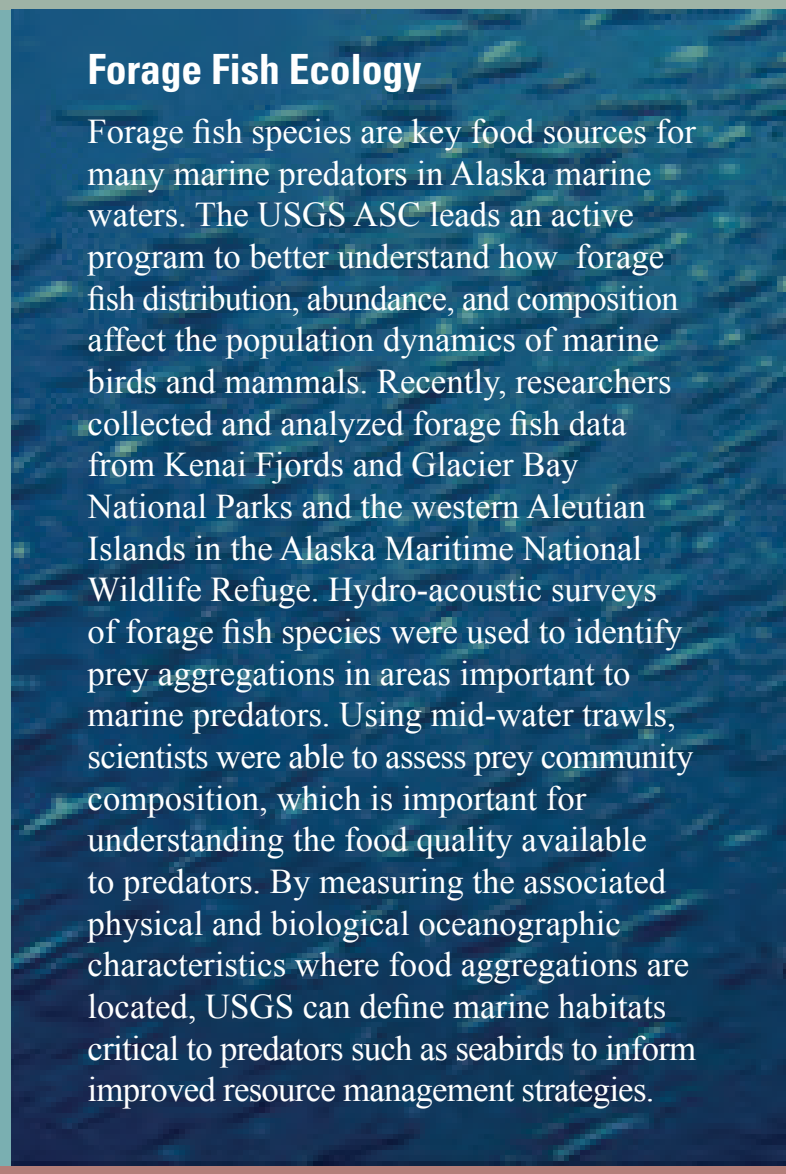

\section{Experimental Seabird Colony}

USGS researchers exploit an unusual circumstance on Middleton Island where kittiwakes, normally cliff-nesting birds, occupy the sides of a decommissioned radar tower on the island. By encouraging and augmenting this behavior using artificial ledges, one-way mirror glass, and individual "feeding tubes" at the nest sites, researchers conduct what amounts to a long-term, large-scale experimentsupplemental feeding throughout the breeding season of a sizeable sample of pairs, with unfed pairs as controls. The USGS ASC has sustained this endeavor since 1996. Presently, about one-half of the study population consists of known-age birds. In the future, the entire study population will be individuals with a known history since birth. By continuing the protocol of supplemental feeding on Middleton, researchers are in effect creating generations of birds that experience contrasting conditions of

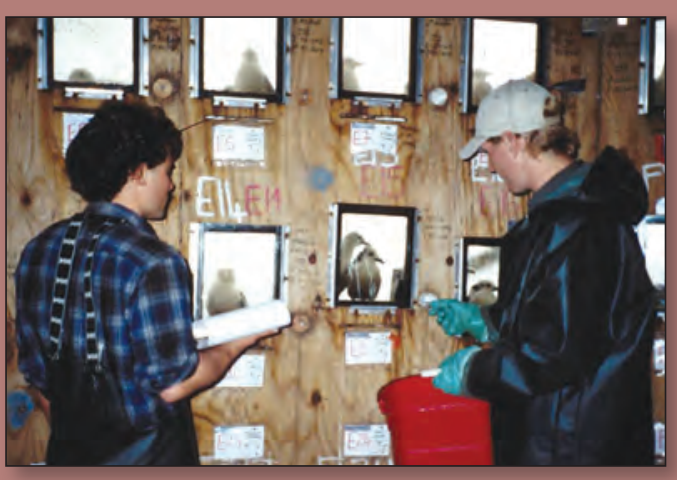
food supply, both during natal development and as breeding adults. This field experimentation is unique in its ability to help parse out the effects of food availability, composition, and environmental factors on the population status of seabirds. 


\section{Providing Science for Resource Managers to Assess Seabirds and Their Habitats Along the Pacific Coast}

\section{Ecology of Vulnerable, Threatened, and Endangered Seabirds}

Seabird research of the USGS WERC is focused on vulnerable, threatened, and endangered species so that resource managers concerned with island and ocean conservation have the best available knowledge to assess seabirds and their habitats - at sea and on land. Current seabird studies use radio- and satellitetelemetry techniques to investigate spatial movement and distribution patterns in diverse habitats ranging from tidally influenced wetlands to remote reaches of the World's oceans.

Research includes at-sea surveys, diet and foraging ecology, reproductive success, science-based island habitat restoration, fisheries conflicts, environmental toxicology, and population enumeration.

\section{Effects of Contaminants on Seabirds in San Francisco Bay}

The USGS WERC is investigating contaminant concentrations and effects on several seabirds, including Forster's Terns, Caspian Terns, and Doublecrested Cormorants in the San Francisco Bay Estuary. The estuary has a legacy of mercury contamination from historical mining activities that has resulted in elevated mercury concentrations in several seabird species. Reproduction is the most sensitive endpoint of mercury toxicity in birds. As many as 58 percent of the Forster's Terns that breed in the South San Francisco Bay are considered

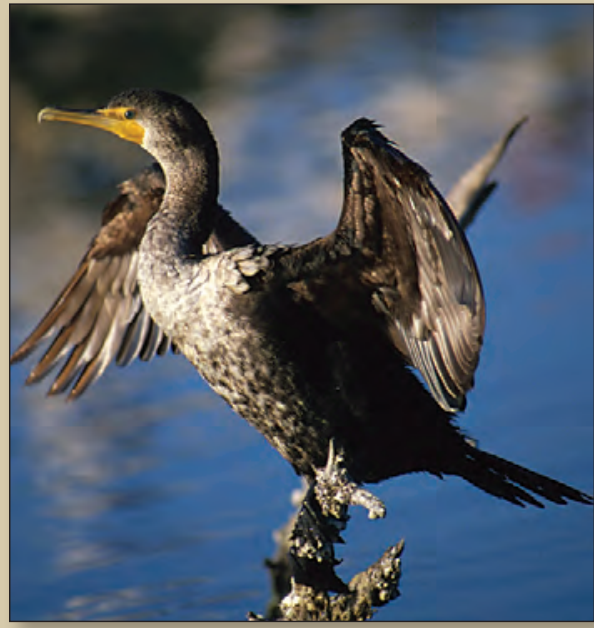

Double-crested Cormorant

at high-risk for mercury contamination.

Scientists have determined that Forster's Tern eggs that have failed-to-hatch have higher mercury concentrations than randomly sampled eggs. Mercury also may be impairing chick growth and survival.

\section{Forster's Tern Reproductive Ecology}

The USGS WERC studies habitat selection, diet, nest success, hatching success, chick growth rates, and survival of Forster's Terns at several colonies in San Francisco Bay. Approximately 30 percent of the Pacific Coast breeding population of Forster's Terns nests in the Bay. The population has remained stable or has slightly declined over the past 20 years and there is concern that the population may be negatively affected by current restoration plans to convert several thousand acres of salt ponds, a preferred habitat for nesting and foraging, into tidal marsh habitat under the South Bay Salt Pond Restoration Project.

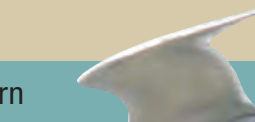

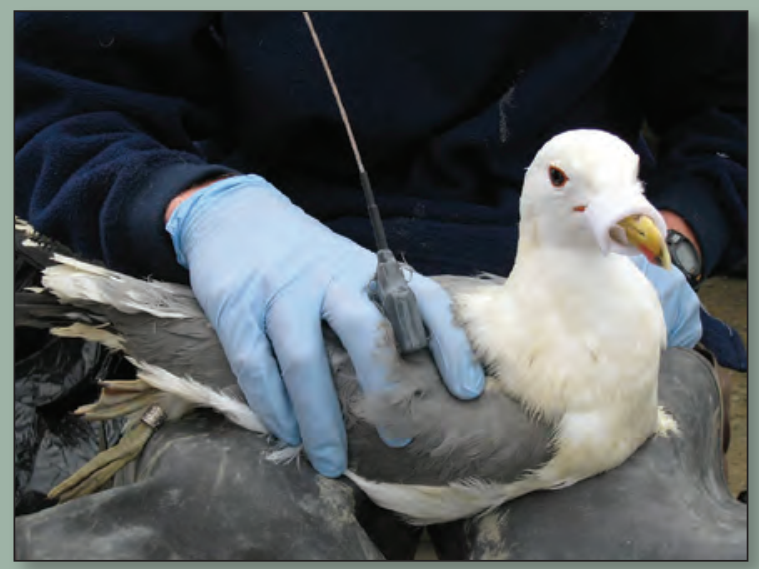

California Gulls

\section{California Gulls}

Breeding populations of California Gulls in San Francisco Bay have increased 37 fold over the past two decades from less than 1,000 breeding birds in 1982 to more than 37,000 in 2007 . Their exponential increase in the bay may be closely related to their use of landfills and other anthropogenic sources of food.

The South Bay Salt Pond Restoration Project plans to restore 16,000 acres of salt ponds into tidal marsh and other habitats, and may cause some of the 37,000 breeding gulls to move to new nesting sites.

California Gulls are voracious predators and are known to kill the young of other coastal birds. Displacement of the largest California Gull breeding colony is of concern. It is unknown where these gulls will disperse to breed but it is likely that many will nest in nearby breeding populations of other nesting waterbirds, including endangered western Snowy Plovers. 


\section{Seabird Monitoring for Hawaił and Pacific Islands}

The USGS Pacific Islands Ecosystems Research Center develops rigorous methods to monitor seabird population status and trends on the National Wildlife Refuges of Hawai' $i$ and the Pacific Islands. The objectives are to assess existing data and monitoring methods and to provide detailed standardized protocols for 13 species to meet seabird management goals. Power analyses and trend assessments have been completed on Black Noddy, Red Footed Booby, Red-Tailed Tropic Birds, and 10 other Pacific seabird species.

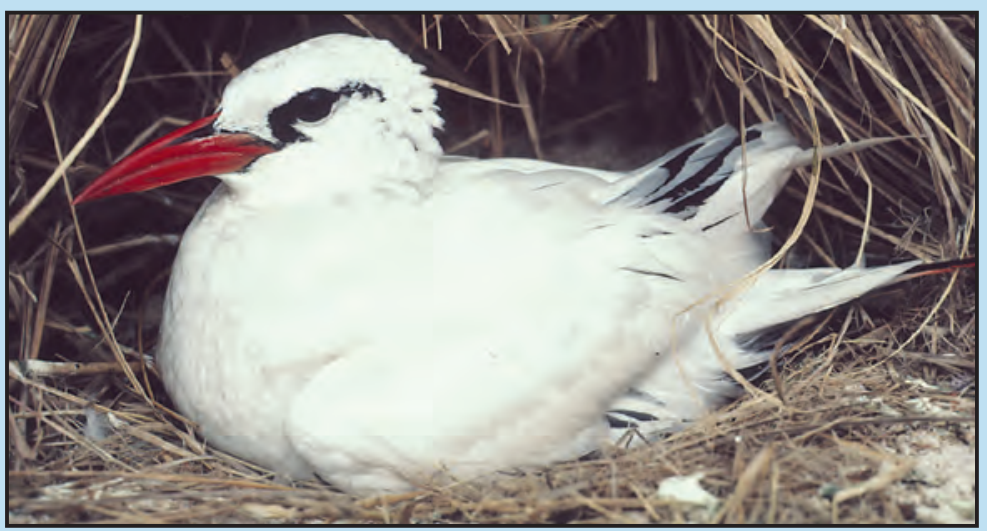

Red-Tailed Tropic Bird

\section{Leading the Way: Developing Pacific Seabird Databases to Facilitate Dissemination of Data}

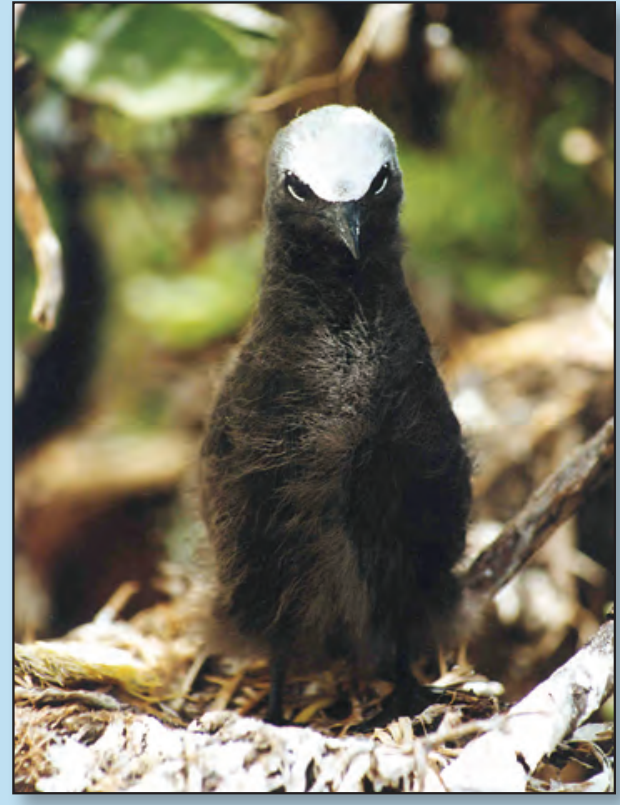

Black Noddy
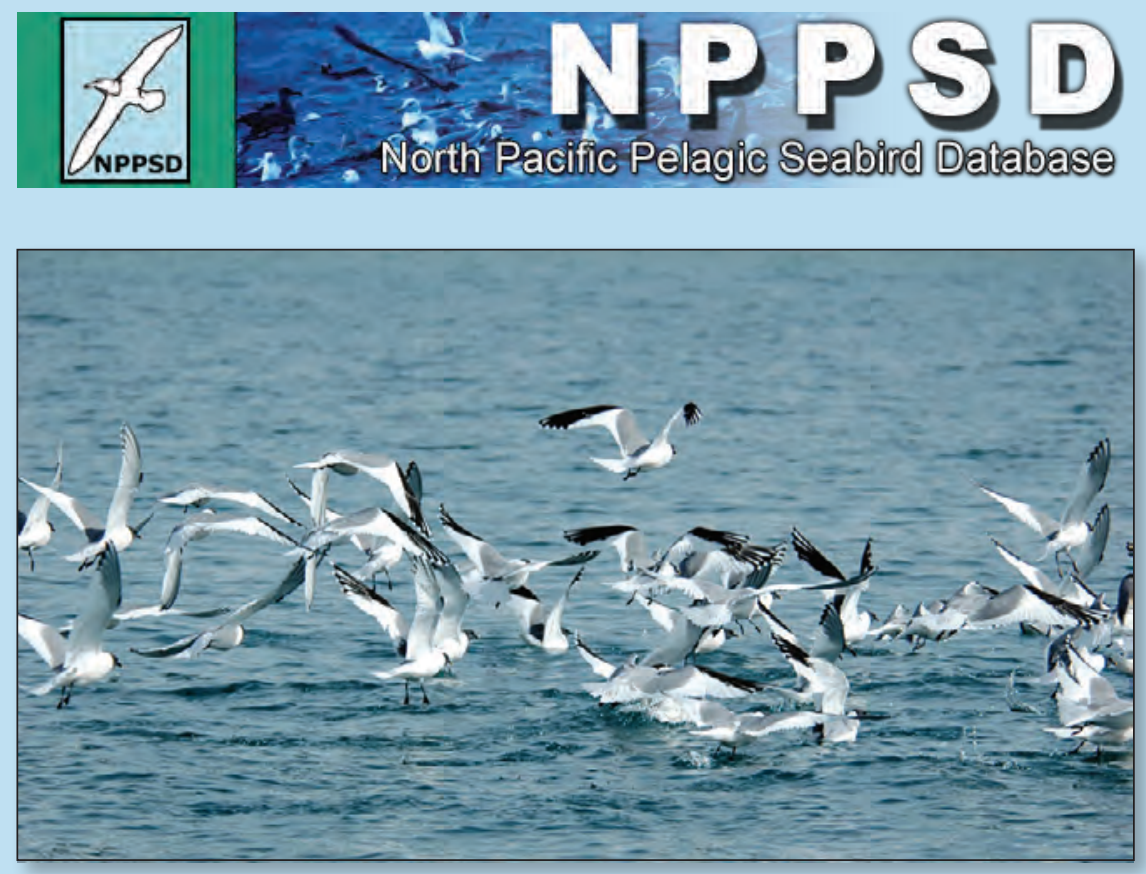

Sabine's Gulls
The USGS ASC is leading the way in development of two major databases on Pacific seabirds. In April 2008, the Pacific Seabird Monitoring Database (PSMD) was launched on behalf of scores of scientists throughout the North Pacific. The PSMD contains vital statistics on breeding biology and diet gathered on multiple species nesting at colonies scattered along the North American coast and across the Pacific basin. Another database, the North Pacific Pelagic Seabird Database (NPPSD), complements the PSMD by collating historical data on the distribution and abundance of seabirds at sea throughout the Pacific Basin. The NPPSD has garnered regional, national, and international interest and is being used to assess the effects of oil pollution, to model the effects of human fisheries and offshore development, and to estimate population status and trends.

\section{For more information:}

USGS Western Region Anne E. Kinsinger, Director 909 First Ave. Suite 704,

Seattle, WA 98104

206-220-4578 